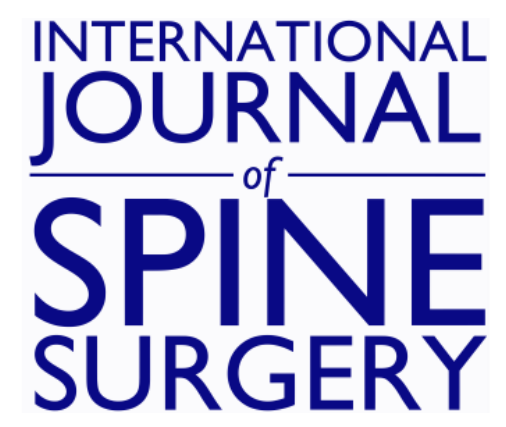

\title{
Comparison Between Gearshift And Drill Techniques For Pedicle Screw Placement By Resident Surgeons
}

Jonathan Allen, Yusuf T. Akpolat, Shyam Kishan, Tim Peppers, Farbod Asgarzadie and Wayne K. Cheng

Int J Spine Surg 2015, 9 ()

doi: https://doi.org/10.14444/2023

http://ijssurgery.com/content/9/23

This information is current as of April 26, 2023.

Email Alerts Receive free email-alerts when new articles cite this article. Sign up at:

http://ijssurgery.com/alerts

The International Journal of Sdoing Surgehth: 2397 Waterbury Circle, Suite 1,

Aurora, IL 60504, Phone: +1-630-375-1432 


\section{Comparison Between Gearshift And Drill Techniques For Pedicle Screw Placement By Resident Surgeons}

Jonathan Allen, MD, ${ }^{1}$ Yusuf T. Akpolat, MD, ${ }^{1}$ Shyam Kishan, MD, ${ }^{2}$ Tim Peppers, MD, ${ }^{3}$ Farbod Asgarzadie, MD, ${ }^{4}$ Wayne K. Cheng, MD ${ }^{1}$

${ }_{1}^{1}$ Department of Orthopaedic Surgery, Loma Linda University ${ }^{2}$ Department of Orthopaedic Surgery, Indiana University ${ }^{3}$ Department of Orthopaedic Surgery, Seaside Spine ${ }^{4}$ Department of Neurological Surgery, Loma Linda University

\section{Abstract}

Background

Various techniques have been described for pedicle screw placement with established clinical and radiological success. Suboptimal screw trajectories can compromise bony purchase and, worse yet, cause neurological and vascular injuries. Thus, it is of paramount importance to achieve maximum accuracy of screw placement. Our objective is to evaluate the accuracy of pedicle screw placement in the thoracolumbar spine by resident surgeons. Two popular techniques, gearshift versus drill, were compared.

Methods

This is a cadaveric surgical technique comparison study. Six resident surgeons instrumented the spine from T1 to S1 using both gearshift and drill techniques. Each pedicle was randomly assigned to either of the techniques. Pedicle screws were placed freehand without radiographic guidance. Violations (medial, lateral, anterior, superior and inferior) were recorded by studying the computerized tomographic scans of instrumented cadavers by blinded observers. Critical perforations were defined as greater than $2 \mathrm{~mm}$ breach of the pedicle wall.

Results

A total of 100 vertebrae (200 pedicles) were instrumented in the six cadavers. 103 pedicles were breached (51.5\% of total pedicles). Lateral violations were the most encountered (65\% of violations, 67 total, 48 critical, 19 noncritical) followed by medial (24\%, 25 total, 13 critical, 12 noncritical), and the rest were anterior (3\%), superior (4\%) and inferior (4\%). There was no overall difference in violations comparing the gearshift technique (49.5\%, 51 total, $37 \mathrm{criti}$ cal, 14 noncritical) with drill technique (50.5\%, 52 total, 33 critical, 19 noncritical). Analyzing the breaches at individual vertebra indicated most violations at T6 (11), T5 (10), followed by T3 (9) and T4 (9), decreasing towards the lumbosacral vertebrae.

\section{Conclusion}

The results of this study suggest that the gearshift and drill techniques for placement of pedicle screws in the thoracolumbar spine fare similarly with regards to risk of breach when applied by resident surgeons.

KEYWORDS: PEDICLE SCREW INSTRUMENTATION, RESIDENT SURGEON, GEARSHIFT, DRILL, PEDICLE VIOLATION, CORTICAL VIOLATION, CRITICAL VIOLATION, NONCRITICAL VIOLATION, VERTEBRAL SEGMENT, ACCURACY, SAFETY.

VOLUME 9 ARTICLE 23 DOI: 10.14444/2023

\section{Introduction}

Pedicle screw fixation is widely used in spinal fusion and has been shown to have a high success rate. A recent meta-analysis ${ }^{1}$ of 130 studies reported a high success rate of $91.3 \%$. However, the procedure is also associated with complications arising from pedicle perforation such as neurological and vascular injuries. $^{2-4}$ Thus, it is of paramount importance to achieve maximum accuracy of screw placement.
Various techniques have been described for pedicle screw placement with established clinical and radiological success. The freehand funnel Gearshift technique is one of the traditional methods of pedicle screw placement and is routinely used to instrument the thoracolumbar spine using anatomical landmarks. ${ }^{5,6}$ The drill technique is gaining popularity for pedicle screw instrumentation and there is published cadaveric and clinical evidence documenting the success of both these methods. ${ }^{7,8}$ Although these techniques are routinely used, there is limited informa- 
tion on the comparative evaluation of these methods. Grauer and colleagues ${ }^{9}$ previously compared a modified drill (Safepath - a proprietary device) with traditional gearshift method in the cadaveric thoracolumbosacral spine and the modified drill technique performed better in the lumbar spine and significantly worse outcomes with the thoracic spine.

Experienced spine surgeons use either of the techniques with good success rates; the objective of our study, however, was to evaluate and compare the accuracy of these methods when employed by resident surgeons. The resident surgeons had no prior experience with drill technique and had limited skills with the gearshift technique, thus allowing for an unbiased comparison. Accuracy of the instrumentation was evaluated by computerized tomographic (CT) scans of the cadavers.

\section{Materials and Methods}

Surgical Procedure and Study Design

All residents underwent a didactic training session which included: anatomy, surgical concepts, and instructions on the gearshift and drill techniques for pedicle screw instrumentation by experienced spine surgeons. This was followed by a hands-on training session using sawbone spines under the guidance of orthopaedic and neurosurgery attendings for both methods (gearshift and drill) before actual instrumentation. Each resident was required to place 24 screws on the sawbone.

All screws were placed using landmarks defined by Kim et al. ${ }^{10}$ in thoracic spine, and Magerl ${ }^{11}$ in the lumbar spine. Starting holes were created using a high speed surgical burr (Midas Rex Legend, Medtronic, Minneapolis, MN) with a match head drill bit of $1.7 \mathrm{~mm}$. For gearshift technique Figure 1A), a Lenke probe (Holmed LLC., Franklin, MA) was used to gain access to the pedicle and vertebral body. A ball tip feeler was used to look for breaches in the pedicle wall. A tap between 4.5 to $7.5 \mathrm{~mm}$ was used following the trajectory, then a pedicle screw between 5.5 and $8.5 \mathrm{~mm}$ ( $1 \mathrm{~mm}$ larger than the tap) was inserted. For drill technique Figure 1B), a 2.5 $\mathrm{mm}$ drill bit (Synthes, Monument, CO) on an Synthes drill driver was used to gain access to the pedi- cle. A ball tip feeler was used to look for breaches in the pedicle wall. A 3.5 drill was then used to enlarge the trajectory, followed by pedicle screws from 5.5 to $8.5 \mathrm{~mm}$.

Each resident was assigned one cadaver and provided with preoperative anteroposterior and lateral full size 17-inch scoliosis radiographs for familiarization of the underlying osseous pathology and pedicle morphology. Each vertebra had pedicle screw instrumentation using both techniques by random assignment of the left and right pedicles. Anatomical landmarks were identified. The residents started instrumentation from the lower spine and proceeded towards the cephaled vertebrae of the spine (S1 followed by lum-

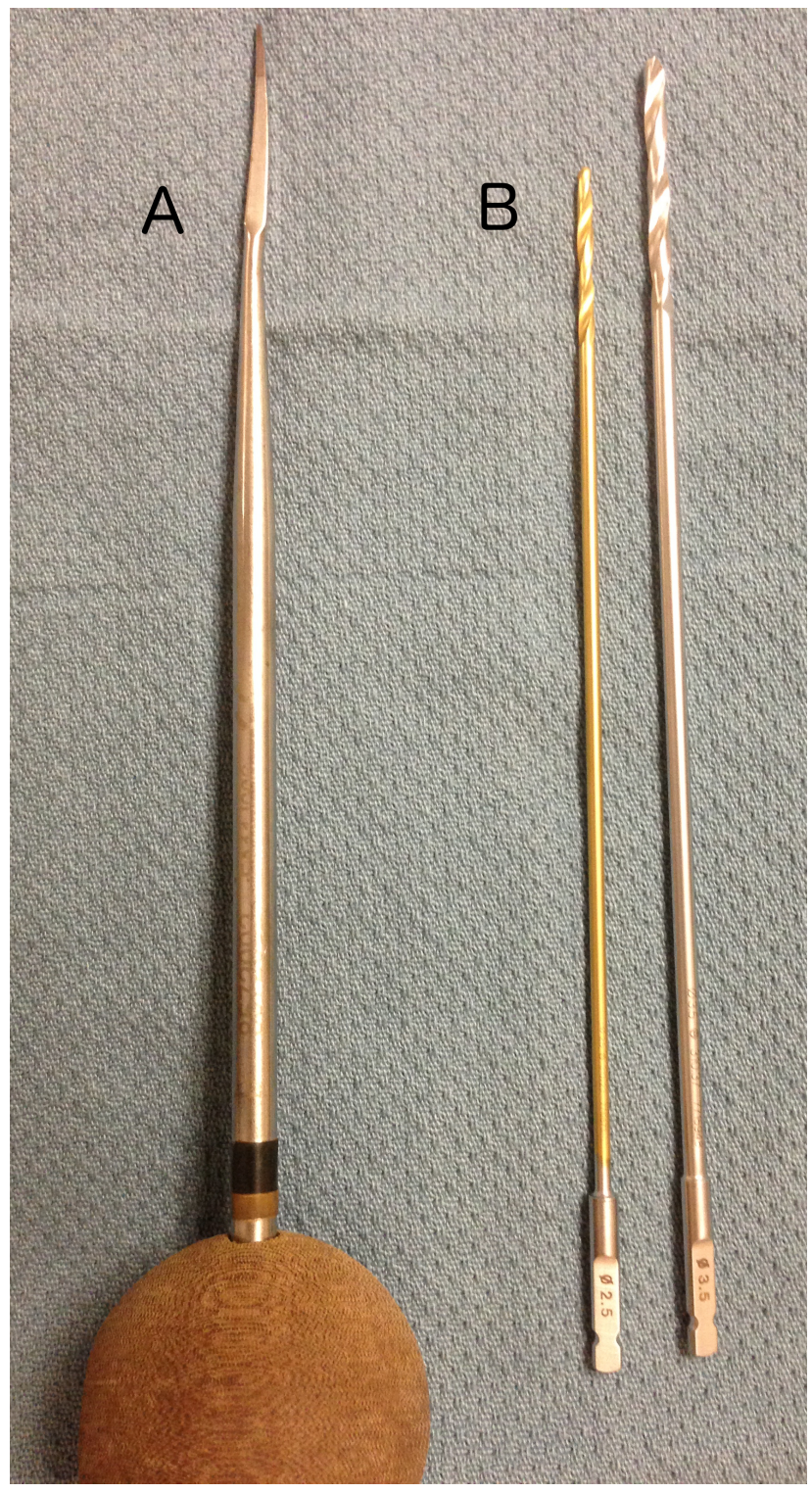

Fig. 1. A, Gearshift. B, Drill. 
bar followed by thoracic). The resident determined the screw size based on radiographic pedicle size and depth of ball-tip probe palpation. Screws of 4.5 to 8.5 $\mathrm{mm}$ diameter were available for instrumentation.

Three orthopaedic surgery residents and three neurosurgery residents volunteered as the study subjects. Two orthopaedic residents had one year of postgraduate training, one orthopaedic resident had two years of postgraduate training and the neurosurgery residents had three, four, and five years of postgraduate training, respectively. The residents that had different levels of training, however, had no prior experience of drill technique and varying, but limited level of experience with gearshift technique.

Six adult cadavers of either sex were used for this study. The soft tissues including the paraspinal muscles were dissected simulating the real operating room condition. A total of one hundred vertebrae (two hundred pedicles) were available for instrumentation in the thoracolumbosacral spine among the six cadavers.

\section{Evaluation of Instrumentation}

Post-instrumentation, computerized tomographic scans (Light Speed 16 Multi Detector, GE Medical System, Fairfield, CT) were obtained for the instrumented spine in each cadaver. CT scans have previously been shown to have extremely high sensitivity in predicting pedicle penetration compared to the gold standard, i.e. direct observation by dissection. ${ }^{9,12}$ The scans were read by a blinded observer for violations: medial, lateral, anterior, superior and inferior. Critical violation was defined as a breach more than $2 \mathrm{~mm}$ according to previous reports, while noncritical violations were those with $2 \mathrm{~mm}$ and below cortical breach.

\section{Statistical Analyses}

T-test and chi-square analyses were used.

\section{Results}

Overall Results

A total of 100 vertebrae (200 pedicles) were available for instrumentation among the six cadavers. 103 pedicles were breached (51.5\% of total pedicles). Lat- eral violations were the most encountered (65\% of violations, 67 total, 48 critical, 19 noncritical) followed by medial (24\%, 25 total, 13 critical, 12 noncritical) and the rest were anterior (3\%), superior (4\%) and inferior (4\%). This is summarized in Figure 2. Analyzing the breach for individual resident, percentage of violation rate per instrumented pedicle is mentioned in Figure 3.

\section{Gearshift versus Drill}

There were a total of 51 violations using the gearshift method (49.5\%, 37 critical, 14 noncritical) and 52 with the drill technique $(50.5 \%, 33$ critical, 19 noncritical as depicted in Figure 4. There was no overall difference in violations comparing the gearshift technique with drill technique ( $\mathrm{p}$ value $=0.6$ ).

\section{Number of Violations versus Spinal Level}

Analyzing the breaches at individual vertebra indicated most violations at T6 (11), T5 (10), followed by T3 (9) and T4 (9), decreasing towards the lum-

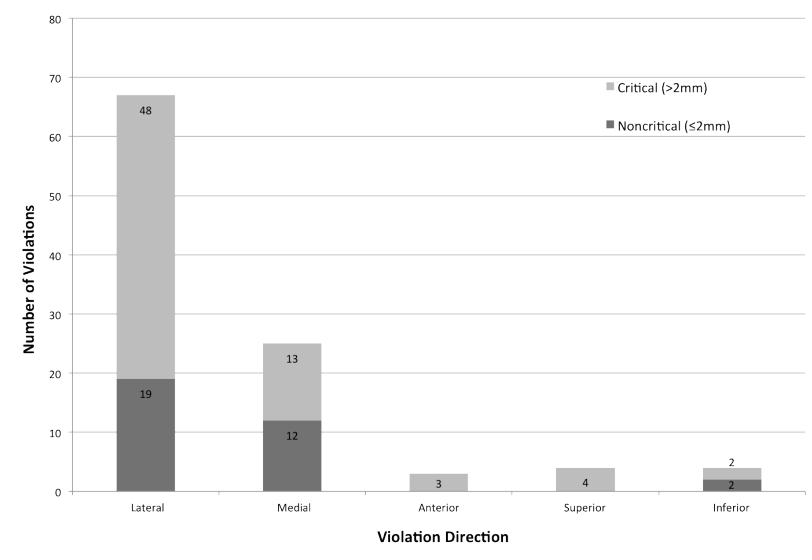

Fig. 2. Number of violations by direction.

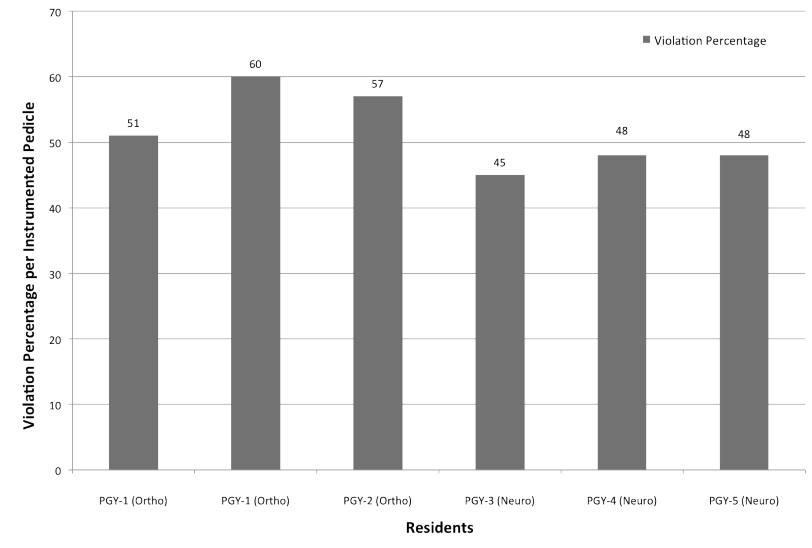

Fig. 3. Violation percentage per pedicle by individual residents.

Downloaded from http://ijssurgery.com/ by guest on April 26, 2023 
bosacral vertebrae Figure 5. Further analysis demonstrated that when the pedicles were grouped into segments (upper thoracic [T1-6]: 14 noncritical, 32 critical; lower thoracic [T7-12]: 8 noncritical, 21 critical; and lumbar [L1-5, S1]: 11 noncritical, 17 critical), there was a statistically higher violation rate in the upper thoracic vertebrae ( $\mathrm{p}$ value .016). This data is summarized in Figure 6.

\section{Discussion}

In the present cadaveric study, we have shown that the accuracy of gearshift and drill techniques is similar when used by resident surgeons for pedicle screw instrumentation in the thoracolumbosacral spine. We noted that the total number of pedicles breached using both techniques in our study were high at $51.5 \%$. A previous report using similar free-hand surgical techniques by Vaccaro et al..$^{13}$ showed $41 \%$ violation

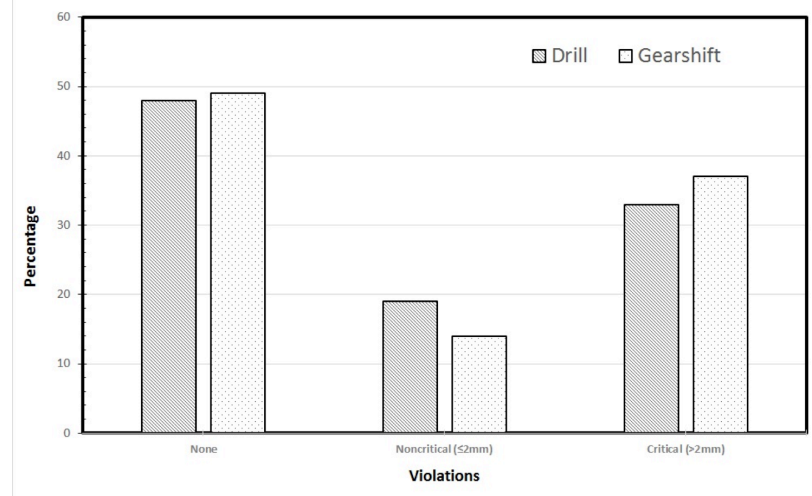

Fig. 4. Violation comparison between gearshift and drill methods for pedicle screw placement. *No differences between drill and gearshift technique $(p=0.6)$.

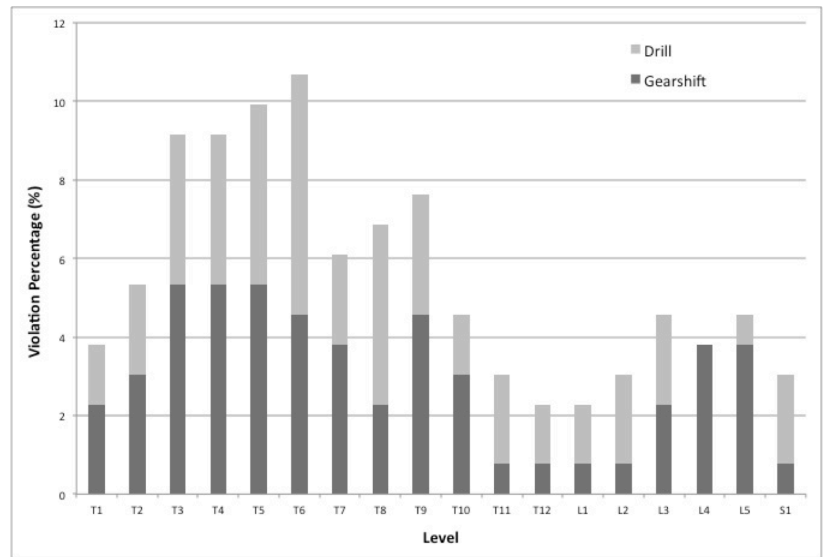

Fig. 5. Violation percentage by vertebral level of gearshift and drill techniques. rate for pedicle screw placement in the thoracic spine by five renowned expert surgeons. Another report by Grauer et al. ${ }^{9}$ comparing Safepath and gearshift techniques demonstrated a $40 \%$ violation rate in the thoracolumbosacral spine. The violation rate in this project was higher, and can be accounted for by a number of factors. Grauer's study did not exchange their pedicle probes for screws, which they acknowledged was not a clinical practice, and exchanging for screws would potentially lead to more violations. Other factors that could contribute to the high breach rate may be due to the experience of our resident physicians which is presumptively significantly less than expert surgeons in the above mentioned papers. A recent study assessing the accuracy of pedicle screw placement by novice surgeons showed an overall violation rate of $29 \%$ in the thoracic spine. ${ }^{5}$ In that study, however, completely dissected and isolated vertebrae mounted on Plexiglas were utilized. Our study was designed to instrument the spine in an intact cadaver to represent the operating circumstances and may be more useful in the setting of surgical training. ${ }^{14}$ The free-hand technique without the aid of fluoroscopic guidance was used in this study because we wanted our subjects to focus on tactile feedback of both surgical techniques rather than depending on image guidance to improve their accuracy.

There is a natural tendency for the surgeon to overcompensate in order to avoid a critical medial breach and potential neurological injury. ${ }^{9}$ In our study, the majority of the violations were lateral breaches of the pedicles (65\% of violations, 67 total, 48 critical, 19 noncritical). Similar findings were noted in previous

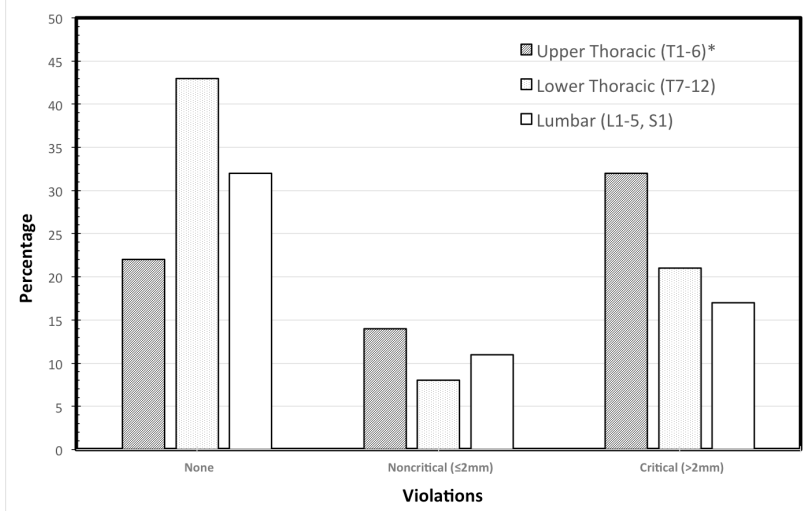

Fig. 6. Comparison of segmental anatomic level with cortical violations. *Statistically higher violation rate $(p=0.016)$. 
retrospective clinical studies by Belmont and colleagues, ${ }^{15,16}$ who noted significantly higher lateral breaches compared to other violations in the thoracic spine. They also noted a much higher rate of violation at higher thoracic level (T1-T8) which dropped towards the caudal end of the thoracic spine. Others, too, have noted a higher rate for lateral violations, ${ }^{9}$ especially in the thoracic spine likely due to the narrow pedicle size and thinner lateral cortical wall. ${ }^{17}$ Our data showed the most violations at $\mathrm{T} 6$ followed by $\mathrm{T} 5$, and $\mathrm{T} 3-\mathrm{T} 4$. The violations decreased towards the lumbosacral spine.

There were multiple limitations of this study. Even though a high fidelity model was used, soft tissue and paraspinal musculature dissection was not standardized. With only one cadaveric specimen per resident, the learning curve was limited to the vertebral bodies available. Further studies may aim to compare multiple successive cadaveric specimens to assess cortical breach from the first specimen to the last to see if cortical violations decrease with short term experience. Multiple data points were not included in this study, including, but not limited to: time taken for screw placement between gearshift and drill techniques, multiple variables related to the resident surgeon (i.e. handedness, level of training, total time taken, etc.), and screw size related to cortical breach. Prior cross sectional pedicle measurements may also aid in fewer cortical breaches.

We intentionally used inexperienced resident surgeons for this experiment in order to decrease potential bias from prior surgical experience. This could be considered as both the strength and weakness of the paper. The best technique for the individual surgeon is often the one the surgeons were trained to use and are most comfortable with. Therefore, this study may also suggest that surgeons could be trained to use either one of the proposed techniques for pedicle screw placement and ultimately learn how to instrument safely and accurately. An interesting follow-up study to demonstrate this point could be repeating this experiment with experienced attending surgeons.

The strengths of this study lie in direct comparison of two popular and routinely used techniques for pedicle screw instrumentation. Moreover, the study subjects had limited experience in either of these techniques thus enabling an unbiased comparison of the methods. The assessment of violations was based on CT scans. CT scans are highly accurate in predicting pedicle breaches when compared to the gold standard for pedicle violation, i.e. direct observation after dissection or other modalities such as radiographs. ${ }^{9,12,18}$ However, there is still a possibility of error. To minimize this, we reduced the thickness of CT slices to $1 \mathrm{~mm}$ as compared to $2.5 \mathrm{~mm}$ in previous studies. ${ }^{9}$ The CT scans were analyzed by a blinded observer; however, the possibility of intra-observer variability was not ruled out and will be addressed in future studies.

\section{Conclusion}

The results of this study suggest that the gearshift and drill techniques have similar breach rates when applied by resident surgeons for placement of pedicle screws in the thoracolumbar spine. Our data coincide with previous studies, showing a higher number of cortical violations in the upper thoracic spine as compared to lower levels. There are more lateral than medial violations for both surgical techniques.

\section{References}

1. Kosmopoulos V, Schizas C. Pedicle screw placement accuracy: a meta-analysis. Spine. 2007 Feb 1;32(3):E111-20. PubMed PMID: 17268254.

2. Esses SI, Sachs BL, Dreyzin V. Complications associated with the technique of pedicle screw fixation. A selected survey of ABS members. Spine. 1993 Nov;18(15):2231-8; discussion 8-9. PubMed PMID: 8278838.

3. Abumi K, Shono Y, Ito M, Taneichi H, Kotani Y, Kaneda K. Complications of pedicle screw fixation in reconstructive surgery of the cervical spine. Spine. 2000 Apr 15;25(8):962-9. PubMed PMID: 10767809. 4. Katonis P, Christoforakis J, Kontakis G, Aligizakis AC, Papadopoulos C, Sapkas G, et al. Complications and problems related to pedicle screw fixation of the spine. Clinical orthopaedics and related research. 2003 Jun(411):86-94. PubMed PMID: 12782863. 
5. Bergeson RK, Schwend RM, DeLucia T, Silva SR, Smith JE, Avilucea FR. How accurately do novice surgeons place thoracic pedicle screws with the free hand technique? Spine. $2008 \mathrm{Jul}$ 1;33(15):E501-7. PubMed PMID: 18594448.

6. Suk SI, Kim WJ, Lee SM, Kim JH, Chung ER. Thoracic pedicle screw fixation in spinal deformities: are they really safe? Spine. $2001 \mathrm{Sep}$ 15;26(18):2049-57. PubMed PMID: 11547207.

7. Kantelhardt SR, Bock CH, Larsen J, Bockermann V, Schillinger W, Rohde V, et al. Intraosseous ultrasound in the placement of pedicle screws in the lumbar spine. Spine. 2009 Feb 15;34(4):400-7. PubMed PMID: 19214101.

8. Lu S, Xu YQ, Zhang YZ, Li YB, Xie L, Shi JH, et al. A novel computer-assisted drill guide template for lumbar pedicle screw placement: a cadaveric and clinical study. The international journal of medical robotics + computer assisted surgery : MRCAS. 2009 Jun;5(2):184-91. PubMed PMID: 19280584. 9. Grauer JN, Vaccaro AR, Brusovanik G, Girardi FP, Silveri CP, Cammisa FP, et al. Evaluation of a novel pedicle probe for the placement of thoracic and lumbosacral pedicle screws. Journal of spinal disorders \& techniques. 2004 Dec;17(6):492-7. PubMed PMID: 15570120.

10. Kim YJ, Lenke LG, Bridwell KH, Cho YS, Riew $\mathrm{KD}$. Free hand pedicle screw placement in the thoracic spine: is it safe? Spine. $2004 \mathrm{Feb}$ 1;29(3):333-42; discussion 42. PubMed PMID: 14752359.

11. Magerl FP. Stabilization of the lower thoracic and lumbar spine with external skeletal fixation. Clinical orthopaedics and related research. 1984 Oct(189):125-41. PubMed PMID: 6478690. 12. Rao G, Brodke DS, Rondina M, Dailey AT. Comparison of computerized tomography and direct visualization in thoracic pedicle screw placement. Journal of neurosurgery. 2002 Sep;97(2 Suppl):223-6. PubMed PMID: 12296683.

13. Vaccaro AR, Rizzolo SJ, Balderston RA, Allardyce TJ, Garfin SR, Dolinskas C, et al. Placement of pedicle screws in the thoracic spine. Part II: An anatomical and radiographic assessment. JBJS (Am). 1995 Aug;77(8):1200-6. PubMed PMID: 7642665.
14. Hamstra SJ, Dubrowski A, Backstein D. Teaching technical skills to surgical residents: a survey of empirical research. Clinical orthopaedics and related research. 2006 Aug;449:108-15. PubMed PMID: 16760810.

15. Belmont PJ, Jr., Klemme WR, Dhawan A, Polly DW, Jr. In vivo accuracy of thoracic pedicle screws. Spine. 2001 Nov 1;26(21):2340-6. PubMed PMID: 11679819.

16. Belmont PJ, Jr., Klemme WR, Robinson M, Polly DW, Jr. Accuracy of thoracic pedicle screws in patients with and without coronal plane spinal deformities. Spine. 2002 Jul 15;27(14):1558-66. PubMed PMID: 12131718.

17. Kothe R, O'Holleran JD, Liu W, Panjabi MM. Internal architecture of the thoracic pedicle. An anatomic study. Spine. 1996 Feb 1;21(3):264-70. PubMed PMID: 8742200.

18. Sapkas GS, Papadakis SA, Stathakopoulos DP, Papagelopoulos PJ, Badekas AC, Kaiser JH. Evaluation of pedicle screw position in thoracic and lumbar spine fixation using plain radiographs and computed tomography. A prospective study of 35 patients. Spine. 1999 Sep 15;24(18):1926-9. PubMed PMID: 10515018.

\section{Disclosures}

Tim Peppers is a paid consultant for Orthofix and receives royalties from Lanx, Inc. The other authors declare no relevant financial disclosures.

\section{Corresponding Author}

Wayne K. Cheng MD, Head, Spine Services, Department of Orthopaedic Surgery, Loma Linda University, School of Medicine, 11406 Loma Linda Drive, Suite 213 Loma Linda, California 92354.

md4spine@yahoo.com

Published 11 June 2015.

This manuscript is generously published free of charge by ISASS, the International Society for the Advancement of Spine Surgery. Copyright @ 2015 ISASS. To see more or order reprints or permissions, see http://ijssurgery.com. 